\title{
UAV-Borne, LiDAR-Based Elevation Modelling: An Effective Tool for Improved Local Scale Urban Flood Risk Assessment
}

\section{Katerina Trepekli ( $\sim$ atr@ign.ku.dk)}

University of Copenhagen: Kobenhavns Universitet https://orcid.org/0000-0002-9040-4409

\section{Thomas Balstrøm}

University of Copenhagen: Kobenhavns Universitet

Thomas Friborg

University of Copenhagen: Kobenhavns Universitet

Bjarne Fog

University of Copenhagen: Kobenhavns Universitet

Albert N. Allotey

CSIR: Council of Scientific \& Industrial Research

Richard Y. Kofie

CSIR: Council of Scientific \& Industrial Research

Lasse Møller-Jensen

University of Copenhagen: Kobenhavns Universitet

\section{Research Article}

Keywords: LiDAR, UAV, urban flooding, Arc-Malstrøm, point cloud classification, Ghana

Posted Date: July 1st, 2021

DOI: https://doi.org/10.21203/rs.3.rs-162102/v1

License: (c) (1) This work is licensed under a Creative Commons Attribution 4.0 International License.

Read Full License 
UAV-borne, LiDAR-based elevation modelling: an effective tool for improved local scale urban flood risk assessment

\section{Author information}

5 Katerina Trepekli ${ }^{1}$, Thomas Balstrøm ${ }^{1}$, Thomas Friborg ${ }^{1}$, Bjarne Fog ${ }^{1}$, Albert N. Allotey ${ }^{2}$, Richard Y. Kofie ${ }^{2}$, Lasse

6 Møller-Jensen ${ }^{1}$

$7{ }^{1}$ Department of Geosciences and Natural Resource Management, University of Copenhagen, Øster Volgade 10, 1350

8 Copenhagen K, Denmark

$92{ }^{2}$ Institute for Scientific \& Technological Information, Council for Scientific \& Industrial Research, P.O. Box CT-2211

10 Cantonments, Accra, Ghana

11 Corresponding author: Katerina Trepekli email: atr@ign.ku.dk

Abstract. In this study we present the first findings of the potential utility of miniaturized Light and Detection Ranging (LiDAR) scanners mounted on Unmanned Aerial Vehicles (UAVs) for improving urban flood assessment at the local scale. This is done by generating high spatial resolution Digital Terrain Models (DTM) featuring buildings and urban microtopographic structures that can affect floodwater pathways (DTMbs). The accuracy and level of detail of the flooded areas simulated by a hydrologic screening model (Arc-Malstrøm), were vastly improved when DTMbs of $0.3 \mathrm{~m}$ resolution representing three urban sites surveyed by a UAV-LiDAR in Accra, Ghana, supplemented a commercially available 10 $m$ resolution DTM covering the full catchment area of the region. The generation of DTMbs necessitated the effective classification of UAV-LiDAR point clouds using a morphological and a triangulated irregular network method for hilly and flat landscapes, respectively. The UAV-LiDAR enabled the identification of archways, boundary walls and bridges that were critical when predicting precise runoff courses that could not be projected using the DTM only. Variations in a stream's geometry due to a one-year time gap between the satellite-based and UAV-LiDAR datasets were also observed. The application of the coarser DTM produced an overestimation of water flows equal to 15\% for sloping terrain and up to $62.5 \%$ for flat areas when compared to the respective runoff simulated using the DTMbs. The application of UAVLiDAR may enhance the effectiveness of urban planning by projecting precisely the location, extent and runoff of flooded areas in dynamic urban settings.

Keywords: LiDAR; UAV; urban flooding; Arc-Malstrøm; point cloud classification; Ghana

\section{Declarations}

Funding: This research is funded by a grant awarded by the Danish Ministry of Foreign Affairs (Danida)

Conflicts of Interest: The authors declare no conflicts of interest.

Authors' Contributions: Conceptualization, Lasse Møller-Jensen, Thomas Friborg, Katerina Trepekli, Bjarne Fog; Formal analysis, Katerina Trepekli, Thomas Balstrøm, Bjarne Fog; Collection of data, Katerina Trepekli, Thomas Friborg, 
40 Climate variability will result in the occurrence of natural disasters that are beyond our socio-economic planning levels when encompassing more intense and frequent large-scale hazards like floods (IPCC 2012; EU Directive 2007). At present, up to 250 million people live on land below annual flood levels, as indicated by high accuracy digital elevation models (DEMs) in contrast to corresponding coarser resolution satellite-based DEMs estimating that 28 million people are affected by riverine floods and 65 million impacted by coastal inundation (Kulp and Strauss 2019). In USA, floods were the fourth-costliest type of extreme climate disasters (NOOA 2020) while the exposure of Sub-Saharan African countries' floods account for $80 \%$ of life losses and $70 \%$ of economic losses (World Bank 2010). In the absence of adaptation, it is projected that 300 million people will face the effects of floods or inundations at least once a year by 2050 and depending on how successfully carbon emissions are reduced, annual coastal flooding could impact between 280 and 640 million people by the end of this century (Kulp and Strauss 2019; Hirabayashi and Kanae 2009).

Based on physical reasoning, projected heavy rainfalls and temperature changes imply possible increases in local flooding in catchments or regions (Hoegh-Guldberg et al. 2018). Changes in flood magnitudes and extents have been reported to be strongly dependent on local topographic conditions (Veijalainen et al. 2010). Population growth, aging infrastructure, alterations in land cover resulting from unplanned urbanization, are significant factors for higher damage potential.

For an effective proactive management, technological developments of remote sensing observations and hydrological models may facilitate rapid flood forecast maps aiming at foreseeing storm-water consequences days in advance of the actual flooding, as well as identification of high-risk areas and flooding extents. However, precise flooding prediction may be hindered when using outdated satellite data or data of poor spatial resolution too coarse to identify local obstacles along the runoff's paths causing he local flooding.

In the current study we evaluated the importance of high spatial resolution surface elevation data in relation to modelling and prediction of flood prone areas in Accra, Ghana. The coastal metropolitan is exposed to great flood risk, as it is rapidly expanding, and urban planning is not able to fully regulate settling to an extent where flooding at a local level can be avoided.

Many of the existing physical-based hydrological models rely on publically available Digital Terrain Models (DTMs) that represent the bare earth surface, only, with a relatively low spatial resolution, as produced by satellite-based Digital Surface Models (DSMs) (e.g., ASTER, STRM) or airborne-based imagery (Zhang and Crawford 2020). The application of low-resolution DSMs that refer to the elevation of the surface with natural and manmade objects (such as building and trees) may also introduce inaccuracies in flood hazard modelling because meter-wide ground features can create a critical difference in simulated flooding (Leitão et al. 2016). Misrepresentation of bridges, tunnels or continuous walls may result in biased estimations of the direction and amount of water flow by neglecting their important downstream effects on urban water resources (Sampson et al. 2012; Becek 2014; Brazier et al. 2016). Thus, to generate more realistic surface pathways, fine resolution DTMs $(<1 \mathrm{~m})$ featuring buildings and urban structures critical to water flow (hereafter DTMb) is required. The application of Light and Detection Ranging (LiDAR) technology may address this challenge by generating spatial information in three dimensions in the form of point cloud data and extracting DEMs of considerably higher resolution throughout floodplains quickly and affordably. However, airborne-based LiDAR datasets are still not available worldwide especially in developing countries due to economic constraints, and similar to satellite/airborne imagery, airborne LiDAR systems cannot always generate DEMs at fine temporal resolution. Alternatively, mobile and terrestrial LiDAR systems 
have been utilized to improve the vertical accuracy of topographic feature representation in DSMs as compared to those acquired by airborne systems (Brasington et al. 2012). The limited field-of-view of the ground-based LiDAR, though, may produce a variety of artefacts in floodwater depth grids (Fewtrell et al. 2011). One of the main challenges to derive DTMbs for flood modelling applications from airborne or mobile LiDAR point cloud data, is their classification into terrain, vegetation, buildings, and potentially important urban objects during floods, like elevated roads, bridges, boundary walls. Numerous filtering algorithms have been suggested for classification of point clouds, like the morphological-based (Zhang et al. 2003), slope-based (Vosselman 2000) or the triangular irregular networks (TIN) (Axelsson 2000), but there is no single classification method applicable for all landscape types (Abdullah et al. 2012; Zhang et al. 2013).

Previous studies have pointed at the potential for predicting urban flooding at the local scale, using DSMs generated by Unmanned Aerial Vehicle (UAV) - photogrammetry coupled with surveyed ground control points (Coveney and Roberts 2017). Schumann et al. (2019) and Izumida et al. (2017) described the utility of DSMs obtained by UAV-imagery as a supplement to airborne LiDAR datasets for flood simulations by comparing the role of accuracy for the respective DSMs in quantifying topographic alterations on floodplains. According to this approach, 3D surface information in the form of point clouds can be generated from different viewpoints of overlapping photos taken by a digital camera and using the Structure for Motion (SfM) method (Westoby et al. 2012; Triggs et al. 2000). However, digital imagery is often challenged by problems with feature definitions due to surface smoothing and difficulties when tuning the image-matching algorithms (Priestnall et al. 2000). The precision of DTMs derived from UAV-imagery depends strongly on the surface characteristics with the largest errors occurring over dense vegetation masking the ground (Govedarica et al. 2018) because the SfM approach cannot create sufficient terrain points in these areas, and since high vegetation must be removed from the terrain analysis, the remaining gaps incommode the surface reconstruction (Hashemi-Beni et al. 2018).

The newly developed technology of UAV-based LiDAR systems can combine: i) the flexibility of conducting spatially continuous, frequent, non-laborious but cost-effective surveys of near-surface remote sensing, especially in locations that are unsafe to access, ii) the generation of topographic data of higher spatial and temporal resolution as compared to aircraft-based LiDAR scanners or satellite/airborne imagery, and iii) the ability to penetrate pervious surfaces as compared to drone borne imagery that cannot map ground levels underneath the vegetation. To the authors' knowledge, the potential utility of UAV-LiDAR systems in flood modelling to identify local areas of high risk has not been reported.

Within the current research's framework, we explored the use of UAV borne LiDAR elevation datasets as a method for mapping areas in risk of flooding in selected flood prone areas of Accra, and hypothesized that such high-resolution data increases the precision in flood estimations at the local scale. For this purpose, we initially evaluated the effectiveness of morphological-based and TIN algorithms to classify the point clouds acquired by UAV-LiDAR surveys over three urban sites in order to produce DTMbs representing terrain, buildings and manmade features which may have a substantial effect on flood propagation. Then we applied a hydrologic screening method (Arc-Malstrøm), recently developed by Balstrøm and Crawford (2018) to assess stormwater induced runoff volumes and identify the local landscape sinks where the runoff gets trapped within the urban settings. The inputs to the hydrologic screening model was: i) a $10 \mathrm{~m}$ DTM purchased from Airbus ${ }^{\mathrm{TM}}$, in lack of publicly available DTMs at semi-low resolution, and ii) $0.5 \mathrm{~m}$ resolution DTMbs generated by a UAV-LiDAR system.

The flood assessment at the full catchment scale provided the quantification of upstream runoff entering the UAVsurveyed sites from the surroundings. Then the hydrologic model was employed at the local scale using the high resolution DTMbs in order to detect the exact location, extent and depth of local landscape depressions (hereafter named sinks) by 
taking into account the pre-estimated upstream Hortonian runoff at various uniform rain events. Flood modelling results were presented in a GIS environment and compared in terms of their potential to identify the extents and depths of local sinks. The predicted accumulated runoff for selected sinks using the semi-low resolution Airbus DTM and the fine resolution LiDAR borne DTMbs were also compared to estimate potential differences in water balance results. Challenges when processing the point cloud data were also discussed since the choice of an appropriate classification method applied to point cloud data collected by a UAV-LiDAR system to generate optimal DTMbs for flood modelling is still rather unexplored. To ensure accurate representation of finer scale topographic features, randomly selected urban features within the flood-prone test areas were field surveyed by measuring their dimensions. To assess the precision of projected flooded areas at the local scale, extensive field observations documenting local flood hotspots and the height of boundary walls raised to protect premises against worst flood events were collected and accompanied by statements from local informants.

\section{Materials and Methods}

\subsection{Study area}

During the last century Ghana has been challenged by severe floods affecting more than 3.5 million people and causing 567 losses of human lives (EM-DAT 2015). From 2015 to 2018 extreme rainfall events concurrent with the peak of the rainy season in the coastal metropolitan, caused 164 deaths and more than 43,000 people were displaced with damaged properties (Ansah et al. 2020; Marrengane and Croese 2020). It can be reasonably anticipated that the citizens of Accra will experience an increase in urban flood frequency due to the projected increase of precipitation patterns with a $1.5^{\circ} \mathrm{C}$ global warming (Klutse el al. 2018), the rapid urbanization and the absence of mitigation strategies against climate extremes in general, highlighting the urgent need to better understand local flooding in order to deploy early flood-control measures.

The satellite based DTM with 10 m resolution from Airbus acquired on May 9, 2018 covered the major 29,690 ha large drainage basin for the Accra region and additional 57 minor drainage basins covering additional 16,650 ha with outlets into the Gulf of Guinea (Fig. 1). The DTM was hydrologically corrected from 343 digitized polylines where river underpasses or bridges along infrastructures were detected from visual inspections of Esri's Basemaps.

Fig. 1 Drainage basins for the Greater Accra Metropolitan Area identified from Airbus' DTM. The main drainage basin (light blue) covers an area of 29,690 ha. The Euclidean distance from its northernmost region at Aburi to the pour point in the Gulf of Guinea is approximately $35.4 \mathrm{~km}$

From the $19^{\text {th }}$ until the $27^{\text {th }}$ of August, 2019 aerial surveys using a UAV- LiDAR system were conducted in three local communities of Accra: 1) the Santa Maria area which is a partially planned, consolidated and densely populated settlement (2106 persons per $\mathrm{km}^{2}$ ) with lots of informal developments consisting of many un-engineered link roads and without properly constructed stormwater-drains. Flooding has been reported to occur in key sections of roads close to a main road. The landscape includes a steep hill nearby the low lying urban area; 2) The University of Ghana Campus (hereafter Legon Hall), located approximately $15 \mathrm{~km}$ northeast of the center of Accra, characterized as a very flat terrain accommodating more than 40.000 people; and 3) the Okponglo flat area located in the city center and close to Accra Sports Stadium (Fig. 2). The UAV-LiDAR surveys covered 16.7 ha in Santa Maria, 14.7 ha in Legon Hall and 25.3 ha in Okponglo 
154 Fig. 2 Southern part of the drainage basins covering the Greater Accra Metropolitan Area and locations of the studied areas at Santa Maria (red point), Okponglo (orange point), and Legon Hall (green point)

156

157

158

159

160

161

162

163

164

165

166

167

168

169

170

171

172

173

174

175

176

177

178

179

180

181

182

183

184

185

186

187

188

\subsection{Instrumentation}

Point cloud data were acquired using a UAV-LiDAR System (LiDARSWISS, CH) onboard of a Matrice 600 Pro octocopter. The LiDAR system includes an inertial navigation system (INS) that fuses data from an Inertial Measurement Unit (Oxts micro electro-mechanical systems) and GPS data received by a Global Navigation Satellite System (GNSS) antenna, a beam LiDAR scanner (Quanergy M8), a SONY R10-C camera with 16mm lens, and an integrated data storage unit. The laser scanner's horizontal field of view (FOV) is 360 degrees, and the vertical FOV equals to 20 degrees. The heading accuracy of the laser scanner is 0.10 degrees, and the pitch/roll accuracy equals to 0.05 degrees with an overall accuracy (RMSE) less than $0.03 \mathrm{~m}$. A Trimble Real Time Kinematic GNSS Base Station was also used to provide additional overhead of communicating with the INS. The horizontal positional accuracy of the GPS receiver was $0.05 \mathrm{~m}$ and 0.03 m vertically. The UAV point cloud datasets were in LAS format and georeferenced to UTM WGS84 zone 30N with resulting mean point density equal to 60 points $/ \mathrm{m} 2$. The UAV flights with the LiDAR scanner and the digital camera onboard the drone were performed $60 \mathrm{~m}$ above the ground with a flight speed of $5 \mathrm{~m} / \mathrm{s}$, an $80 \%$ forward overlap and $65 \%$ side overlap specifications. At the Okponglo site the LiDAR dataset's point spacing was $0.08 \mathrm{~m}$, and the point density was 142.86 samples $/ \mathrm{m}^{2}$. The acquired point clouds representing the Santa Maria and Legon Hall sites had a point spacing equal to $0.05 \mathrm{~m}$ and their average point density was 471.14 and 235.17 samples $/ \mathrm{m}^{2}$, respectively.

\subsection{Point cloud data processing for generating DTMb using the UAV-LiDAR}

In this study we assessed the effectiveness of a combination of two morphological-based filters (MM) introduced by Chang et al. (2008) and Zhang et al. (2003), and the TIN algorithm to classify the acquired point cloud data representing the hilly site of Santa Maria and the low-lying area of Okponglo (Fig. 3). The evaluation procedure was based on the comparison of the percentage of points grouped into different classes with the respective point clouds manually classified through visual inspection of the derived surfaces, and with recourse to aerial imagery of the sites. Manual filtering was employed previously to evaluate automated filter performance, as filtering errors are often obvious to interpret with the naked eye, and urban features are relatively easy to classify over small areas (Hutton and Brazier 2012; Sithole and Vosselman 2004).

To detect ground points the MM filters were applied to each dataset to initially remove points that are likely non-ground. The remaining points are compared to a modelled 3D curved surface within a series of grids using a multi-scale curvature algorithm to detect the ground points. The parameterization of the morphological filters included alteration of the values for the size of the area where points are compared to their neighbors (bin size), as well as alterations of the allowed height change from the local averaged minimum, at which points are removed from the ground classification in order to model a curved ground surface. The classification of buildings and trees was based on a morphological-based algorithm that relies on the points' relationship to a calculated best-fit planar surface within each bin of the LiDAR data (Blue Marble Geographics 2020). The required minimum height above the ground for a potential building or high vegetation point was 
set to $1.7 \mathrm{~m}$ in order to include continuous boundary walls and exclude other objects like bushes and cars. Bridges were detected following the segmentation method introduced by Sithole and Vosselman (2006). The TIN refinement algorithm was applied to the LiDAR dataset to perform a comparative classification of the point cloud using the LAStools software by Rapidlasso $\mathrm{GmbH}$. The search step size that defines the average building size, and the maximal standard deviation for planar patches (i.e., building planarity and tree ruggedness) were tested to optimize the number of ground, building and tree points.

After the classification of non-ground points, objects like trees and bridges were removed to avoid water flow blocking in the stormwater simulations. The remaining points were interpolated using the inverse-distance weighting method (Shepard 1968) in order to rasterize the point clouds at $0.3 \mathrm{~m}$ resolution (DTMbs).

Fig. 3 Point cloud data derived by UAV-LiDAR, illustrating areas of a) Santa Maria, b) Okponglo and c) Legon Hall

\subsection{Hydrologic screening method}

Two or three-dimensional hydraulic models update flood propagation through timesteps, but their computational complexity can be proportional to the resolution desired (Noh et al 2018). Alternatively, a computer program can be used that simulates flood flows all across the floodplain coupled with a spatial analysis software that turns the model results into map layers that can be overlaid with building layers, land use maps etc. Leitão et al. (2009) demonstrated that accurate 1-D overland flow networks in urban areas can be achieved when DEMs of fine resolution are utilized. The storm-water screening method (Arc-Malstrøm) is based on a representation of the surface in a 1D network not involving any hydrodynamic components nor time, but it is well suited to provide a quick first overview of the location of sinks, their capacities, contributing watersheds and the accumulated downstream flow when the sinks spill over (Balstrøm and Crawford, 2018). The Arc-Malstrøm model was initially applied to the satellite-based DTM covering the urban area in order to visualize landscape sinks as individual polygons (hereafter named bluespots) with assigned attribute values describing their capacities $\left(\mathrm{m}^{3}\right)$, maximum depths $(\mathrm{m})$, extents $\left(\mathrm{m}^{2}\right)$ and the spillover fields that express the water loads $\left(\mathrm{m}^{3}\right)$ that enter and leave a bluespot along the flow paths, and by considering a specific uniform rainfall event added to the entire drainage basin. The spillover volume from a bluespot (SpillOverOut) is calculated for a given rain event, $\mathrm{xx}$ $(\mathrm{mm})$, by the formula: SpillOverOut_xx = SpillOverIn_xx + RainVolume_xx - Capacity, where SpillOverIn is the runoff volume $\left(\mathrm{m}^{3}\right)$ entering the bluespot from upstream, RainVolume is the runoff volume $\left(\mathrm{m}^{3}\right)$ generated within the bluespot's watershed, and Capacity is the bluespot's volume $\left(\mathrm{m}^{3}\right)$ below its pour point level. Various precipitation scenarios were tested ranging from 20 to $150 \mathrm{~mm}$. Identified local sinks shallower than $0.2 \mathrm{~m}$ and smaller than $1 \mathrm{~m}^{3}$ were excluded from the flood simulations in order to eliminate puddles along infrastructures and preserve deeper and more voluminous sinks. The estimated water volumes from the surrounding upstream sinks spilling over at each studied site were used to determine the incoming water flow that contributed to a $30 \mathrm{~mm}$ rainfall scenario in order to model the flood at the local scale using the high resolution DTMbs as inputs to the hydrologic model. The presented hydrologic attributes were simulated at the local scale considering the relative conservative scenario of $30 \mathrm{~mm}$ precipitation because most of the detected sinks within the three surveyed sites were predicted to be already filled after a $30 \mathrm{~mm}$ rain event based on flood simulation at the city-wide scale.

\section{Results and discussion}




\subsection{Classification of point cloud data}

228 For the low-lying flat area of Okponglo, the MM approach had a better overall performance compared to the TIN but 229 almost half of the point clouds that should represent buildings remained unclassified (Table 1). On the other hand, the 230 TIN approach was more effective in classifying the building points using a step size equal to $25 \mathrm{~m}$ and a building planarity 231 equal to 0.1.

232 The optimal parameterization set for the MM approach that led to a more accurate ground classification consisted of a minimum height above the local average minimum elevation at which points were considered as non-ground equal to 0.3 $\mathrm{m}$, and a bin size equal to $0.5 \mathrm{~m}$. The optimal RMSE from a best-fit local plane that building points must be within was $0.2 \mathrm{~m}$ with the respective minimum vegetation distance being equal to $0.3 \mathrm{~m}$. For the ground classification based on the TIN approach, the $5 \mathrm{~m}$ step size was found to be more effective (50.27\%) compared to the $25 \mathrm{~m}$ cell size (47.44\%), but the TIN method could not identify any vegetation points. Noticeable, the choice of optimal step size was critical when reducing the number of faulty rejected ground points (Type I errors) and the number of faulty accepted non-ground points (Type II errors). The smaller window size preserved the terrain details, but large building features were not filtered completely leading to high Type II errors. The larger window removed large objects effectively, but the terrain details were overlooked leading to high Type I errors.

Table 1 Percentage of classified points and the resulting elevation range between manually classified datasets compared to the respective classified point clouds after the application of the TIN method and a combination of the slope-based and morphological based-algorithm (MM).

\begin{tabular}{|c|c|c|c|c|c|c|}
\hline Site & Okponglo & & & Santa Maria & & \\
\hline Method & TIN & MM & Reference & TIN & MM & Reference \\
\hline Ground & $\begin{array}{l}47.44 \\
(71.57- \\
83.27 \mathrm{~m})\end{array}$ & $\begin{array}{l}56.25 \\
(71.57-79.82 \mathrm{~m})\end{array}$ & $\begin{array}{l}59.47 \\
(71.97- \\
79.70 \mathrm{~m})\end{array}$ & $\begin{array}{l}39.2 \\
(41.47- \\
52.69 \mathrm{~m})\end{array}$ & $\begin{array}{l}38.37 \\
58 \mathrm{~m})\end{array}$ & $\begin{array}{l}49.85(40.25- \\
58.51 \mathrm{~m})\end{array}$ \\
\hline Building/ walls & $\begin{array}{l}20.96 \\
(75.10- \\
83.27 \mathrm{~m})\end{array}$ & $\begin{array}{l}12.13 \\
(73.28-83.27 \mathrm{~m})\end{array}$ & $\begin{array}{l}25.40 \\
(73.07- \\
83.34 \mathrm{~m})\end{array}$ & $\begin{array}{l}21.95 \\
57.37 \mathrm{~m})\end{array}$ & $\begin{array}{l}34.13 \\
54.9 \mathrm{~m})\end{array}$ & $\begin{array}{l}50.15(39.88- \\
58.51 \mathrm{~m})\end{array}$ \\
\hline High vegetation & & $\begin{array}{l}18.21 \\
(73.28-83.27 \mathrm{~m})\end{array}$ & $\begin{array}{l}15.13 \\
(73.00- \\
83.34 \mathrm{~m})\end{array}$ & $\begin{array}{l}16.03 \\
58.51 \mathrm{~m})\end{array}$ & $\begin{array}{l}0.65 \\
54.68 \mathrm{~m})\end{array}$ & $\begin{array}{l}13.11(42.22- \\
53.23 \mathrm{~m})\end{array}$ \\
\hline Unclassified & 31.59 & $\begin{array}{l}13.32 \\
(71.93-83.27 \mathrm{~m})\end{array}$ & & $\begin{array}{l}27.91 \quad(41.80- \\
58.51 \mathrm{~m})\end{array}$ & $\begin{array}{l}22.06 \\
58.50 \mathrm{~m})\end{array}$ & \\
\hline
\end{tabular}

In the case of the Santa Maria site where the physical landscape is generally undulating, interspersed in most parts with plains and gentle slopes compared to the flat area of Okponglo site, the classification of point clouds was optimized using the TIN model tuned at a $5 \mathrm{~m}$ step size, a building planarity equal to 0.2 and a value of tree ruggedness equal to 0.4 . The ground classification's performance using the MM was improved by increasing the minimum height change from the local mean value to $0.5 \mathrm{~m}$ and by decreasing the bin size to $0.25 \mathrm{~m}$ allowing for more low vegetation points to be removed. 
The choice of a suitable filtering algorithm with optimized parameters may become crucial to retrieve the correct dimensions of the buildings and the resulting surface elevations (Table 1). Floodplain biases have been attributed, also, for ineffective filtering of vegetation from the point clouds (Cobby et al. 2001; Schumann et al. 2019), pointing out the significance of evaluating the suitability of classification approaches to the LiDAR datasets prior to the generation of elevation models in order to improve their vertical accuracy. By comparing the filtering methods' performance in these distinctly different urban areas, it was found that the TIN approach could effectively identify the ground points of the hilly site while the morphological-based method produced more competitive outputs in the simulated flat terrain.

\subsection{Flood simulations using UAV-LiDAR DTMbs and semi-low resolution elevation models}

With the Arc-Malstrøm screening tool, the locations, extents and contributing watershed areas of local sinks were derived for the whole urban area using the Airbus' 10 m DTM and visualized in a GIS environment for the three surveyed sites. The bluespots' location, extent, depth, and the stream network for each site simulated at the local scale using the high resolution DTMbs were also illustrated with the respective outputs from the urban-scaled flood modelling (Fig. 4; Fig. 5, Fig. 6). Under the same precipitation scenario, the comparison of bluespots generated by the LiDAR-derived and satellitebased elevation models pointed out differences in their locations and extents within all sites. Some of the projected bluespots' locations for the Santa Maria and Okponglo sites were partially overlapped using both the semi-low and fine resolution surface elevation models (Fig. 4; Fig. 5), but a considerable discrepancy between the locations and the extents of the sinks generated from these approaches was visually evident for the Legon Hall site (Fig. 6).

The observed differences could be attributed to an underestimation of the mean terrain height for each satellite-based 10 m pixels covering each surveyed area that, consequently, would lead to an overestimation of the flooded areas' extents. Overestimation or underestimation of flow modelling may result from substantial errors in the vertical elevations (Bates 2012), but the adaptation of elevation models representing bare earth, only (i.e. Airbus' DTM), may also lead to biases in stream geometries since the effect of buildings and other microtopographic features on the direction of water flow is not taken into account.

Fig. 4 Comparison of bluespot extents in the Santa Maria site as simulated by applying the semi-low resolution DTM and the high resolution DTMb generated by the UAV-LiDAR. The bluespots' depths for flood modelling at the local scale were classified and colored accordingly. Streams are represented by blue lines and watersheds by dashed black lines. Watersheds modelled at the city-wide scale (ID S1, S2 and S3) are represented by black lines

The differences in the derived hydrological attributes in Santa Maria using the satellite-based DTM vs. the UAV-LiDAR DTMb (Fig.4; Table 2) could also be sourced to alterations of the actual topography during the time gap between the UAV-LiDAR campaign and the acquisition of Airbus' DTM (08/2019 and 05/2018, respectively). Although it could be argued that the time gap is relatively short for any significant topographical changes, we observed an alteration in the course of the stream in the Santa Maria site due to reconstruction activities for a bridge at the time of the UAV-LiDAR flights, as documented with an aerial photograph (see also Fig. 12). This area coincide with the simulated sink in Fig. 4 (orange polygon) that has a maximum depth up to $2 \mathrm{~m}$ probably due to the existence of a deep hole at the construction site. At the date of the Airbus' DTM acquisition, an immense trash volume accumulation was noticed along a big river 
(i.e. the Odaw River), dislocation of concrete elements along the tamed river's walls, as well as temporary deep holes close to construction sites in the city center of Accra. Thus, the amount of water that spills from a stream onto adjacent low-lying areas could be influenced by variations in the geometry of channels and rivers resulting from human interference.

Fig. 5 Comparison of bluespot extents in the Okponglo site as simulated by applying the semi-low resolution DTM and the high resolution DTMb generated by the UAV-LiDAR. The bluespots' depths for flood modelling at the local scale were classified and colored accordingly. Streams are represented by blue lines and watersheds by dashed black lines. Watersheds modelled at the city-wide scale (ID O1, O2) are represented by black lines

The generated flood map from the high resolution DTMb for Okponglo revealed the extent of filled sinks that would occur along one major road and a secondary one at a $30 \mathrm{~mm}$ rain event with a maximum sink depth reaching levels of 0.6 $\mathrm{m}$ and $1.6 \mathrm{~m}$, respectively (Fig. 5). The aquaplaning locations that would pose risk to vehicle transportation during floods were also detected from the coarser DTM, but the modelled sinks' extent were larger. The detailed flood modelling pointed out specific buildings that may be surrounded by highly elevated precipitation runoff. For instance, the sinks colored in red in Fig. 5 were considerably deep and narrow, and the resulting runoff volumes may have severe impacts on the existing infrastructure surrounded by these sinks; this pattern was not captured by the flood modelling at the citywide scale.

Fig. 6 Comparison of bluespot extents in the Legon Hall site as simulated by applying the semi-low resolution DTM and the high resolution DTMb generated by the UAV-LiDAR. The bluespots' depths for flood modelling at the local scale were classified and colored accordingly. Streams are represented by blue lines and watersheds by dashed black lines. Watersheds modelled at the city-wide scale (ID L1, L2) are represented by black lines

At the Legon Hall site, pathways underneath arch buildings could be identified in the LiDAR point clouds (Fig. 7). If those archways were misrepresented as continuous structures in the DTMb due to low density of point clouds or top-view imagery, the projected stream network would be diverted, and the sinks' locations and extents would change significantly (Fig. 8a) without maintaining the flood modelling precision (Fig. 8b).

Fig. 7 Extracted point clouds representing archways, trees and concrete fences

Similarly, Meesuk et al. (2015) concluded that the detection of hidden underneath pathways using ground-view images combined with airborne LiDAR data could lead to correct simulations of floodwater dynamics around urban features. Evidently, the precision of terrain characteristics that can be produced by highly dense point clouds, as those obtained by

Fig. 8 Digital Terrain Models featuring building information and excluding vegetation (DTMb) with simulated streams 
327 To quantitatively assess the influence of higher resolution topography on the estimated water balance, the final 328 downstream water flow calculated from the stormwater simulation at the urban scale was compared with the respective 329 total runoff simulated at the local scale within the selected watersheds illustrated in Fig. 4, Fig. 5 and Fig. 6. Overall, the 330 flood simulations at all sites produced shallower bluespots and larger downstream water volumes (27.41\%) after the 331 application of the semi-low resolution DTM (Table 2), most likely due to the smoothening of the Airbus' elevation values that was applied by the vendor to remove artefacts from the DTM after subtracting above ground objects (vegetation and 333 buildings) from the acquired DSM in spite of the fact that the buildings should have been kept, ideally, to represent a $\mathrm{DTMb}$ in order to model the precipitation runoff more correctly around them. Under these conditions, the sinks' capacities can be underestimated causing more precipitation to be converted into surface runoff instead of being trapped within the sinks. For example, the downstream water flow that spills over out of the surveyed area of Santa Maria was relatively overestimated by $12.71 \%$ due to a combination of underestimating the capacity and depth of the bluespot within ID S3 and of overestimating the runoff entering its watershed (i.e. the spill-over vs. the downstream bluespot within ID S2). Thus, from a hydrologic perspective, the $10 \mathrm{~m}$ resolution DTM may not be considered sufficient for precise urban flood modelling, particularly when the interest is focused on localized flow conditions and inundation at the small scale. These findings are in line with other inundation studies (Wang and Zheng 2005; Cook and Merwade 2009) who reported that lower resolution DTMs (from $6 \mathrm{~m}$ to $30 \mathrm{~m}$ ) produced by airborne LiDAR datasets led to higher predicted water levels and flooded areas.

Table 2 Comparison of hydrological attributes after the application of the flood model at the local scale using the DTMb generated by the UAV-LiDAR and at the urban scale using the satellite-based DTM for watersheds of the Santa Maria (S), Okponglo (O) and Legon Hall (L) sites.

\begin{tabular}{|c|c|c|c|c|c|}
\hline & Flood modelling & the local scale & Flood modelling & the urban scale & \\
\hline Watershed ID & Water flow $\left(\mathrm{m}^{3}\right)$ & $\begin{array}{l}\text { Maximum (mean) } \\
\text { depth }(m)\end{array}$ & Water flow $\left(\mathrm{m}^{3}\right)$ & $\begin{array}{l}\text { Maximum } \\
\text { (mean) depth (m) }\end{array}$ & $\begin{array}{l}\text { Difference }(\%) \text { in } \\
\text { water flow }\end{array}$ \\
\hline S1 & 1,211 & $1.63(0.75)$ & 1,434 & 0.2 & 18.42 \\
\hline $\mathrm{S} 2$ & 51,522 & $7.59(1.00)$ & 58,770 & 1.67 & 14.07 \\
\hline S3 & 123,814 & $4.36(1.16)$ & 139,555 & 0.6 & 12.71 \\
\hline $\mathrm{O} 1$ & 128 & $4.7(0.91)$ & 208 & 0.58 & 62.5 \\
\hline $\mathrm{O} 2$ & 30,020 & $8.94(2.44)$ & 35,359 & 1.55 & 17.78 \\
\hline L1 & 182 & $12.6(2.26)$ & 282 & 1.86 & 54.94 \\
\hline L2 & 218 & $3.44(0.63)$ & 243 & 0.21 & 11.47 \\
\hline
\end{tabular}

349 The urban-scaled downstream water flows in the flat sites of Okponglo and Legon Hall were considerably overestimated 350 compared to the respective water volumes simulated at the local scale using the DTMbs by $62.5 \%$ and $55 \%$ for the 1 st 351 order bluespots of the O1 and L1 watersheds, respectively. Similarly, Colby and Dobson (2010) stated that the flood 352 simulations in a low-relief plain were more sensitive to coarsening of LiDAR-derived DTMs compared to a hilly 
landscape. A direct comparison of the present research outputs with studies aiming to simulate flooding based on airborne LiDAR, satellite-based or UAV-based imagery but not on UAV-LiDAR data, is challenging due to differences in data acquisition methods for the elevation models, topographic data resolution, hydrologic modelling and geomorphologic characteristics of the studied sites.

\subsection{Quantitate and qualitative validation of the hydrological modelling at the local scale}

Structural information for 30 randomly selected buildings, boundary walls, bridges and containers, extracted from the UAV-LiDAR point clouds, was highly correlated with field-based measurements consisting of lengths and widths of the selected sample structures $\left(\mathrm{R}^{2}=0.998, \mathrm{RMSE}=0.74 \mathrm{~cm}\right)$. Randomly selected point cloud data representing bridges and underpasses had correct courses when compared to the actual situation documented by aerial photos justifying the accuracy of UAV-LiDAR point cloud data (e.g. Fig. 9).

Fig. 9 Profile view of downstream parts for a small bridge in point cloud format collected by the UAV LiDAR and aerial view of the bridge; both collected for validating the point cloud precision

The ground truth points labelled as 8,10,12 and 16 in Fig. 4 consisted of wall heights equal to $50 \mathrm{~cm}, 100 \mathrm{~cm}, 92 \mathrm{~cm}$, and $85 \mathrm{~cm}$, respectively. In the flood simulations, these ground truth points were located within bluespots with predicted maximum depths ranging from $51 \mathrm{~cm}$ to $1.25 \mathrm{~m}$.

Fig. 10 Ground photos corresponding to the ground truth points 12 and 16 in Fig. 4, where the height of the boundary walls was measured to indicate water levels during floods

Fig. 11 A 3D view of the DTMb for the Santa Maria area surveyed by the UAV-LiDAR, illustrating terrain, buildings and concrete walls. Local sinks (polygons) and streams (lines) were simulated at the local scale

Flood simulations at the local scale obtained by using high-resolution floodplain topographic data indicated that some houses are located critically within some of the bluespots (Fig. 11). The qualitative testimony confirmed that floodwater regularly affects the infrastructure in this area (ground truth points 0,3 and 6 in Fig. 4) due to spill-over from a stream that was clearly outlined as an elongated sink. In the riparian buffer zone along the stream, there is extensive housing development built on or located vis-a-vis waterways, effectively narrowing the channel and impeding the free water flow. The stream receives water from numerous small streams entering from uphill locations north and north-west of the studied site and converging into a low-lying valley (ground truth points 7, 8, 9 and 10). This valley contains many sinks, and it was also highlighted as a notoriously flood-prone location by municipal officials. Field observations indicated visible evidence of road erosion caused by surface run-off in uphill areas, which provides an indication of the water volumes carried downslope (example in Fig. 12b). 
Fig. 12 a) Aerial photograph capturing a location where a flood-prone bridge is enlarged causing a sink with a considerable depth, and b) evidence of erosion in a partial drain due to spill-over from uphill areas

\section{Conclusions}

In this study we presented a workflow for urban flood assessment utilizing UAV-LiDAR technology and a storm-water screening model.

The accuracy and level of detail of the flooded areas' extents, depths and runoff, was vastly improved when the high resolution $(0.3 \mathrm{~m})$ DTMbs generated by the UAV-LiDAR system supplemented a semi-low (10 m) resolution satellitebased DTM in the screening merthod for three urban sites in Accra. The DTMbs included only ground, buildings and geomorphologically important objects during floods.

One of the main advantages of the UAV-LiDAR system was its potential to identify urban microtopographic features such as buildings, boundary walls, bridges, vegetation and archways. Such features have a substantial influence on floodwater pathways and their misrepresentation in DTMbs can generate inaccurate water depths and flood propagation patterns. To improve the vertical accuracy of the DTMbs and, consequently, the precision of flood simulations at the local scale, the effectiveness of LiDAR-derived point cloud classification should be evaluated. A morphological approach and a triangulated irregular network were found to be more suitable to classify UAV-LiDAR datasets representing a hilly and a flat landscape, respectively.

Alterations in stream geometries between the acquisition of satellite data and the experimental campaign was also observed pointing out the utility of UAV-LiDAR for updating the DEMs in areas that might have been undergoing topographic alterations since the last collection of elevation datasets from airborne LiDAR or satellite sensors.

When only the semi-low resolution DTM was considered for flood analysis, the simulated sinks were unrealistically shallower and with larger extents. The respective downstream water flows were overestimated by approximately 15.10 $\%$ for a hilly site and up to $62.5 \%$ for flat urban terrains when compared to the runoff simulated using UAV-LiDAR derived DTMbs.

Flood predictions using the high-resolution elevation data from UAV-LiDAR instrumentation are proposed as an invaluable resource and supplement to existing available airborne or satellite-based products to produce flood maps. Here, we demonstrated that the finer representation of topography and complex urban features from UAV-LiDAR can increase the precision of projected flooded areas, allowing urban planning to be based on actual present-day conditions and securing the most detailed and cost efficient drainage and flood protection in urban settlements at the local scale.

\section{References}

Abdullah AF, Vojinovic' Z, Price RK, Aziz NA. (2012) Improved methodology for processing raw LiDAR data to support urban flood modelling - accounting for elevated roads and bridges. J Hydroinform 14:253-69. https://doi.org/10.2166/hydro.2011.009

Ansah S, Ahiataku M, Yorke C, Otu-Larbi F, Yahaya B, Lamptey P, Tanu M (2020) Meteorological Analysis of Floods in Ghana. Adv Meteorol (Online) 2020: Article ID 4230627 https://doi.org/10.1155/2020/4230627 

Sens 33: 111-118.

Balstrøm T, Crawford D (2018) Arc-Malstrøm: A 1D hydrologic screening method for storm water assessments based on geometric networks. Comput Geosci 116: 64-73. https://doi.org/10.1016/j.cageo.2018.04.010

Bates PD (2012) Integrating remote sensing data with flood inundation models: How far have we got? Hydrol Process 26: 2515-2521. https://doi.org/10.1002/hyp.9374

Becek K (2014) Assessing Global Digital Elevation Models Using the Runway Method: The Advanced Spaceborne Thermal Emission and Reflection Radiometer Versus the Shuttle Radar Topography Mission Case. IEEE Trans Geosci Remote Sens 52:4823-4831. https://doi.org/10.1109/TGRS.2013.2285187

Blue Marble Geographics (2020) https://www.bluemarblegeo.com/knowledgebase/index.php Accessed 19 November 2020

Brasington J, Vericat D, Rychkov I (2012) Modeling river bed morphology, roughness, and surface sedimentology using high resolution terrestrial laser scanning. Water Resour Res 48: W11519. https://doi.org/10.1029/2012WR012223

Brazier RE, Jones L, DeBell L., King N, Anderson K (2016) Water resource management at catchment scales using lightweight UAVs: Current capabilities and future perspectives. J Unmanned Veh Syst 4: 7-30. https://doi.org/10.1139/juvs-2015-0026

Chang C, Habib F, Lee C, Yom H (2008) Automatic classification of lidar data into ground and nonground points. In: International archives of photogrammetry, remote sensing and spatial information sciences, Commission: WG IV/3, Beijing. XXXVII : Part B4.

Cobby DM, Mason DC, Davenport IJ (2001) Image processing of airborne scanning laser altimetry data for improved river flood modelling. ISPRS J Photogramm Remote Sens 56: 121-138. https://doi.org/10.1016/S0924-2716(01)000399

Colby JD, Dobson JG (2010) Flood modeling in the coastal plains and mountains: Analysis of terrain resolution. Nat. Hazards Rev 11: 19-2. https://doi.org/10.1061/(ASCE)1527-6988(2010)11:1(19)

Cook A, Merwade V (2009) Effect of topographic data, geometric configuration and modeling approach on flood inundation mapping. J Hydrol 377: 131-142. https://doi.org/10.1016/j.jhydrol.2009.08.015

Coveney S, Roberts K (2017) Lightweight UAV digital elevation models and orthoimagery for environmental applications: data accuracy evaluation and potential for river flood risk modelling. Int J Remote Sens. 38: 3159-3180. https://doi.org/10.1080/01431161.2017.1292074

Directive 2007/60/EC of the European Parliament and of the Council of 23 October 2007 on the assessment and management of flood risks (Text with EEA relevance). http://data.europa.eu/eli/dir/2007/60/oj Accessed 20 October 2020 
EM-DAT (2015) The OFDA/CRED International Disaster Database, www.emdat.be - Université catholique de Louvain. https://www.emdat.be/. Accessed 16 October 2020

Fewtrell TJ, Duncan A, Sampson CC, Neal JC, Bates PD (2011) Benchmarking urban flood models of varying complexity and scale using high resolution terrestrial LiDAR data. Phys Chem Earth 36: 281-291. https://doi.org/10.1016/j.pce.2010.12.011

Govedarica, M, Jakovljević, G, Alvarez-Taboada, F (2018) Flood risk assessment based on LiDAR and UAV points clouds and DEM. In: Proc. SPIE 10783, Remote Sensing for Agriculture, Ecosystems, and Hydrology XX, 107830B. https://doi.org/10.1117/12.2513278

Hashemi-Beni L, Jones J, Thompson G, Johnson C, Gebrehiwot A (2018) Challenges and Opportunities for UAV-Based Digital Elevation Model Generation for Flood-Risk Management: A Case of Princeville, North Carolina. Sensors, 18: 3843. https://doi.org/10.3390/s18113843

Hirabayashi Y, Kanae S (2009) First estimate of the future global population at risk of flooding. Hydrol Res Lett 3:6-9. https://doi.org/10.3178/hrl.3.6

Hoegh-Guldberg O, Jacob D, Taylor M et al (2018) Impacts of $1.5^{\circ} \mathrm{C}$ Global Warming on Natural and Human Systems. In: Global Warming of $1.5^{\circ} \mathrm{C}$. In Masson-Delmotte V, Zhai P, Pörtner H et al. (ed) An IPCC Special Report on the impacts of global warming of $1.5^{\circ} \mathrm{C}$ above pre-industrial levels and related global greenhouse gas emission pathways, in the context of strengthening the global response to the threat of climate change, sustainable development, and efforts to eradicate poverty. In Press

472 Hutton C, Brazier R (2012) Quantifying riparian zone structure from airborne LiDAR: Vegetation filtering, anisotropic 473 interpolation, and uncertainty propagation. J Hydrol 442-443: 36-45. https://doi.org/10.1016/j.jhydrol.2012.03.043 IPCC (2012). Managing the Risks of Extreme Events and Disasters to Advance Climate Change Adaptation In: Field CB, Barros, V, Stocker TF, Qin, D et al (ed). Available from Cambridge University Press, The Edinburgh Building, Shaftesbury Road, Cambridge CB2 8RU ENGLAND, pp 582

Izumida A, Uchiyama S, Sugai T (2017) Application of UAV-SfM photogrammetry and aerial LiDAR to a disastrous flood: repeated topographic measurement of a newly formed crevasse splay of the Kinu River, central Japan. Nat Hazards Earth Syst Sci 17:1505-1519. https://doi.org/10.5194/nhess-17-1505-2017

480 Klutse N, Vincent O, Gbobaniyi O, et al (2018) Potential impact of $1.5^{\circ} \mathrm{C}$ and $2{ }^{\circ} \mathrm{C}$ global warming on consecutive dry and wet days over West Africa. Environ Res Lett 13:055013. https://doi.org/10.1088/1748-9326/aab37b

482 Kulp SA, Strauss BH (2019) New elevation data triple estimates of global vulnerability to sea-level rise and coastal 483 flooding. Nat Commun 10: Article number: 4844. https://doi.org/10.1038/s41467-019-12808-z 
Leitão JP, Boonya-Aroonnet S, Prodanovic D, Maksimovic C (2009) The influence of digital elevation model resolution on overland flow networks for modelling urban pluvial flooding. Water Sci Technol 60: 3137-3149. . https://doi.org/10.2166/wst.2009.754

Leitão JP, Moy de Vitry M, Scheidegger A, Rieckermann J (2016) Assessing the quality of digital elevation models obtained from mini unmanned aerial vehicles for overland flow modelling in urban areas. Hydrol Earth Syst Sci 20: 16371653. https://doi.org/10.5194/hess-20-1637-2016

Marrengane N, Croese S (2020) Reframing the Urban Challenge in Africa Knowledge Co-production from the South. Taylor \& Francis, eBooks

Meesuk V, Vojinovic Z, Mynett A, Abdullah A (2015) Urban flood modelling combining top-view LiDAR data with ground-view SfM observations. Adv Water Resour 75: 105-117. https://doi.org/10.1016/j.advwatres.2014.11.008

NOAA National Centers for Environmental Information (NCEI) U.S. Billion-Dollar Weather and Climate Disasters (2020), https://doi.org/10.25921/stkw-7w73

Noh SJ, Lee J, Lee S, Kawaike K, JunSeo D (2018) Hyper-resolution 1D-2D urban flood modelling using LiDAR data and hybrid parallelization. Environ Modell Softw 103: 131-145. https://doi.org/10.1016/j.envsoft.2018.02.008

Priestnall, G, Jaafar, J, Duncan, A (2000) Extracting urban features from LiDAR digital surface models. Comput Environ Urban Syst 24:65-78. https://doi.org/10.1016/S0198-9715(99)00047-2

Sampson CC, Fewtrell TJ, Duncan A, Shaad K, Horritt MS, Bates PD (2012) Use of terrestrial laser scanning data to drive decimetric resolution urban inundation models. Adv Water Resour 41:1-17. https://doi.org/10.1016/j.advwatres.2012.02.010

Schumann Guy J-P, Muhlhausen J, Andreadis KM (2019) Rapid Mapping of Small-Scale River-Floodplain Environments Using UAV SfM Supports Classical Theory. Remote Sens 11:982. https://doi.org/10.3390/rs11080982

Shepard D (1968) A two-dimensional interpolation function for irregularly-spaced data. In Proceedings of the 1968 23rd ACM national conference, pp. 517-524.

Sithole G, Vosselman G (2004) Experimental comparison of filter algorithms for bare-Earth extraction from airborne laser scanning point clouds. ISPRS J Photogramm Remote Sens 59: 85-101. https://doi.org/10.1016/j.isprsjprs.2004.05.004

Sithole G, Vosselman G. (2006) Bridge detection in airborne laser scanner data. ISPRS J Photogramm Remote Sens 61, 33-46. https://doi.org/10.1016/j.isprsjprs.2006.07.004

Triggs B, McLauchlan F, Hartley I, Fitzgibbon W (2000) Bundle adjustment - a modern synthesis. In: International Workshop on Vision Algorithms, Springer, pp. 298-372 
514 Turner AB, Colby JD, Csontos RM, Batten M (2013) Flood modelling using a synthesis of multi-platform LiDAR data.

515 Water 5: 1533-1560. https://doi.org/10.3390/w5041533

516 Veijalainen N, Lotsari E, Alho P, Vehvilainen B, Kayhko J (2010) National scale assessment of climate change impacts 517 on flooding in Finland. J Hydrol 391: 333-350. https://doi.org/10.1016/j.jhydrol.2010.07.035

518 Vosselman G (2000) Slope based filtering of laser altimetry data. IAPRS Int Arch Photogramm Remote Sens Spatial Inf 519 Sci 33 (B3): 935-942.

520 Wang Y, Zheng T (2005) Comparison of light detection and ranging and nation elevation dataset digital elevation model 521 on floodplains of North Carolina. Nat Hazards Rev 6: 34-40. https://doi.org/10.1061/(ASCE)1527-6988(2005)6:1(34)

522 Westoby J, Brasington J, Glasser F, Hambrey J, Reynolds M (2012) 'Structure from- motion', photogrammetry: a low523 cost, effective tool for geoscience applications. Geomorphology (Amst) 179:300-14. 524 https://doi.org/10.1016/j.geomorph.2012.08.021

525 World Bank (2010) The World Bank Annual Report 2010: Year in Review. World Bank Annual Report. Washington, 526 DC. (C) World Bank. License: CC BY 3.0 IGO https://openknowledge.worldbank.org/handle/10986/5906 Accessed 12 527 September 2020

528 Zhang Q, Chen C, Whitman D, Shyu L, Yan H, Zhang C (2003) A progressive morphological filter for removing non 529 ground measurements from airborne LiDAR data. IEEE Trans. Geosci. Remote Sens. 41 (4), 872-882. 530 https://doi.org/10.1109/TGRS.2003.810682

531 Zhang, J, Lin X, Ning X (2013) SVM-Based Classification of Segmented Airborne LiDAR Point Clouds in Urban Areas. 532 Remote Sens 2013: 3749-3775. https://doi.org/10.3390/rs5083749

533 Zhang Y, Crawford P (2020) Automated Extraction of Visible Floodwater in Dense Urban Areas from RGB Aerial Photos 534 Remote Sens 12: 2198. https://doi.org/10.3390/rs12142198 
Figures

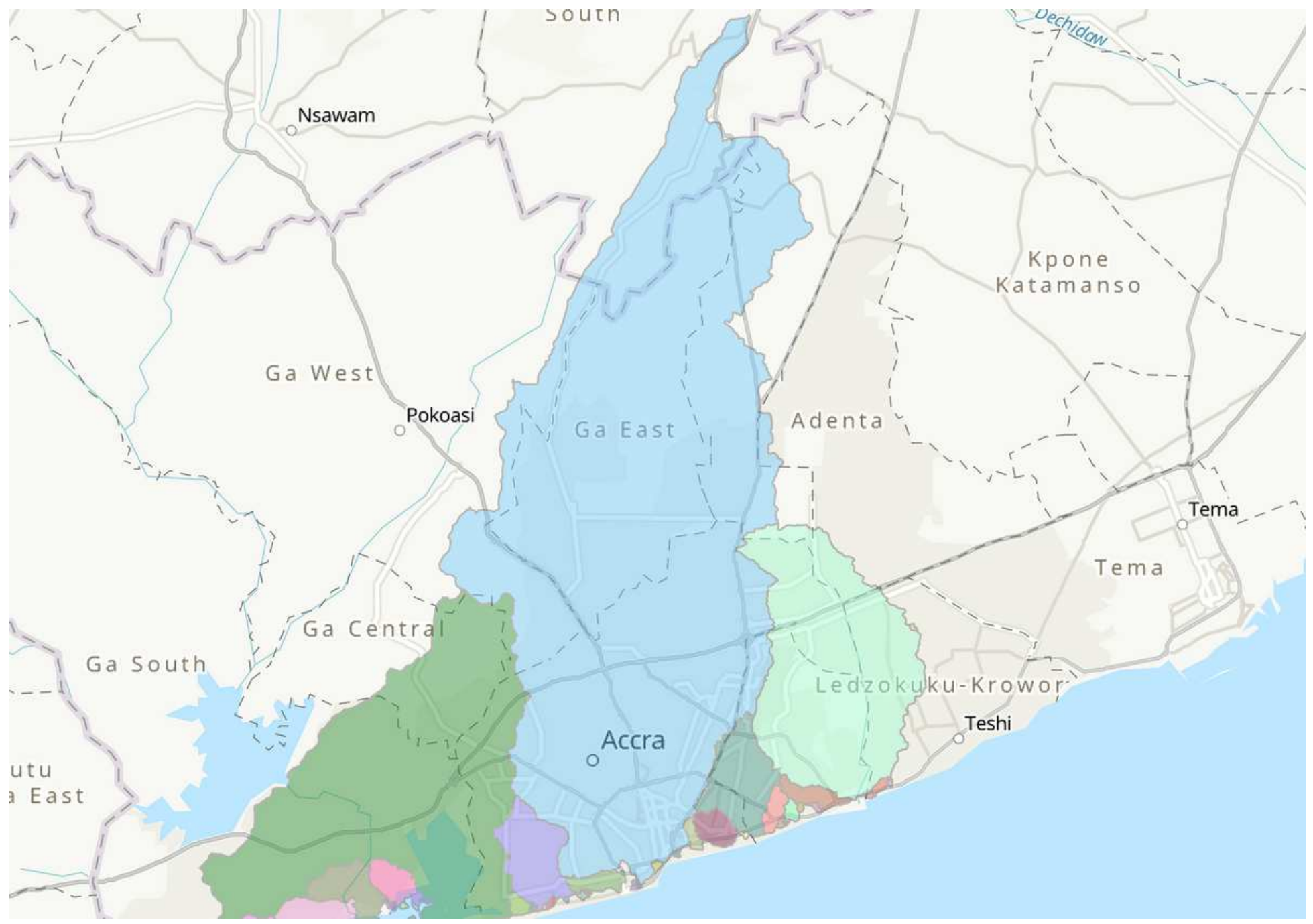

Figure 1

Drainage basins for the Greater Accra Metropolitan Area identified from Airbus' DTM. The main drainage basin (light blue) covers an area of 29,690 ha. The Euclidean distance from its northernmost region at Aburi to the pour point in the Gulf of Guinea is approximately $35.4 \mathrm{~km}$ 


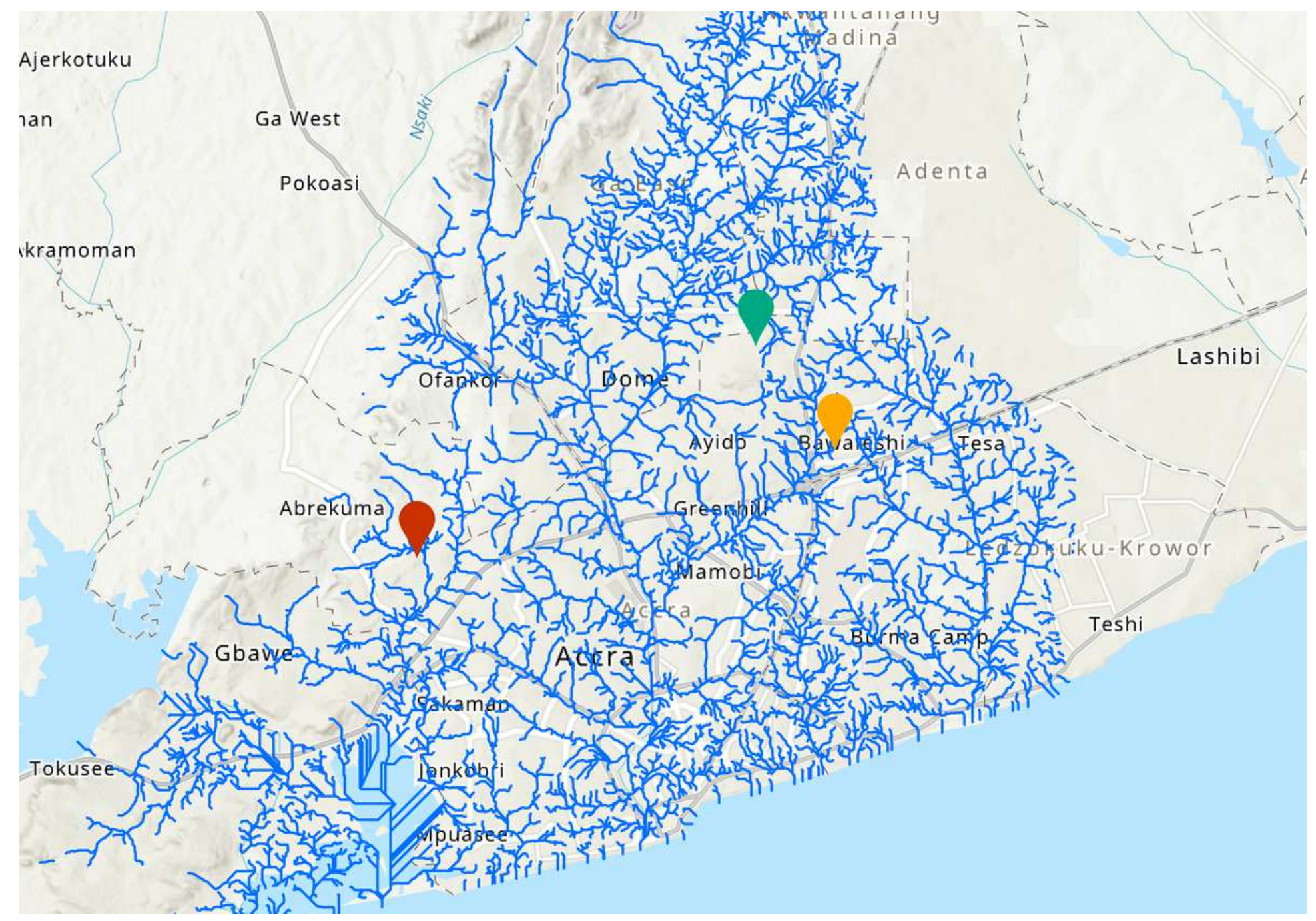

Figure 2

Southern part of the drainage basins covering the Greater Accra Metropolitan Area and locations of the studied areas at Santa Maria (red point), Okponglo (orange point), and Legon Hall (green point) 

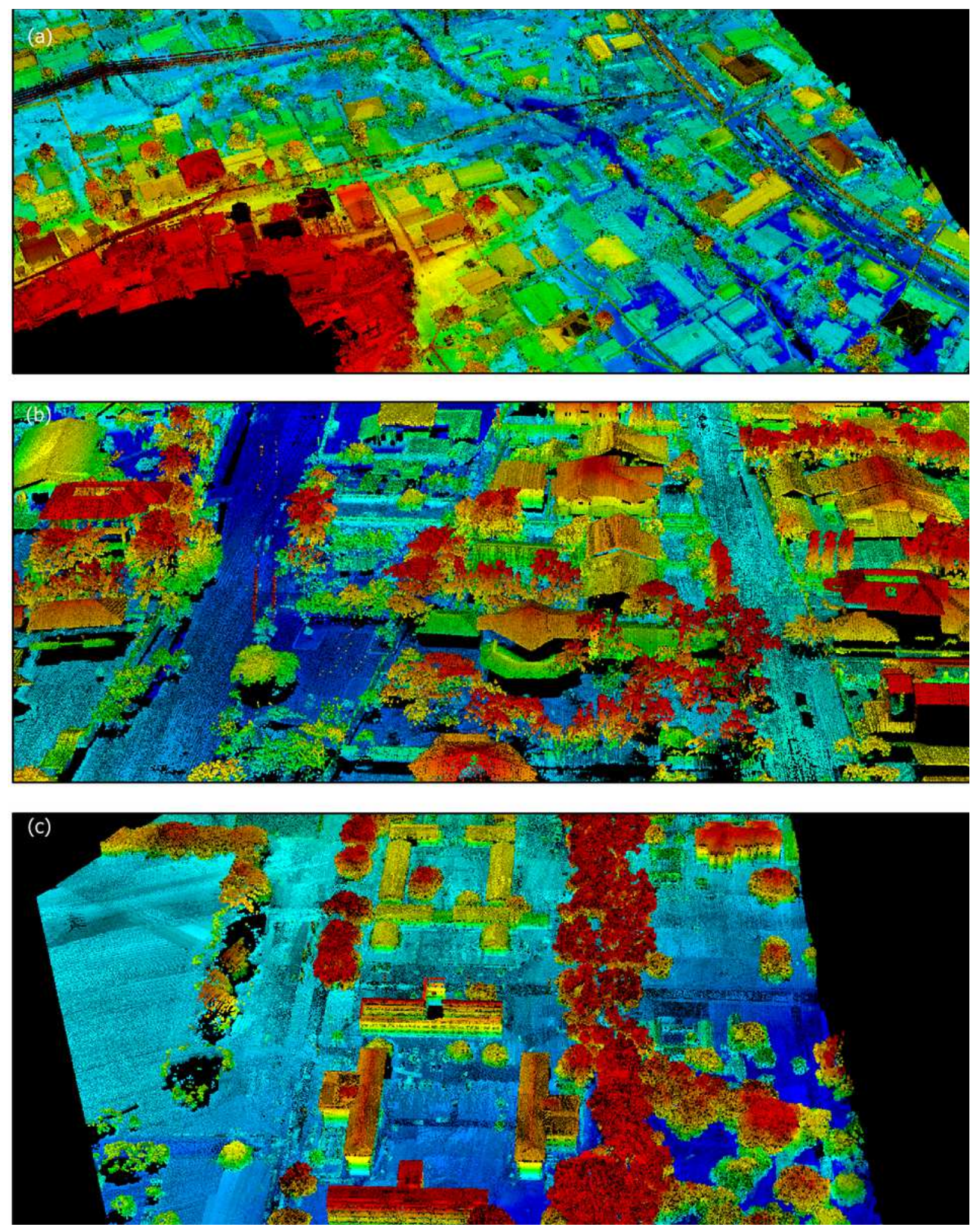

Figure 3

Point cloud data derived by UAV-LiDAR, illustrating areas of a) Santa Maria, b) Okponglo and c) Legon Hall 


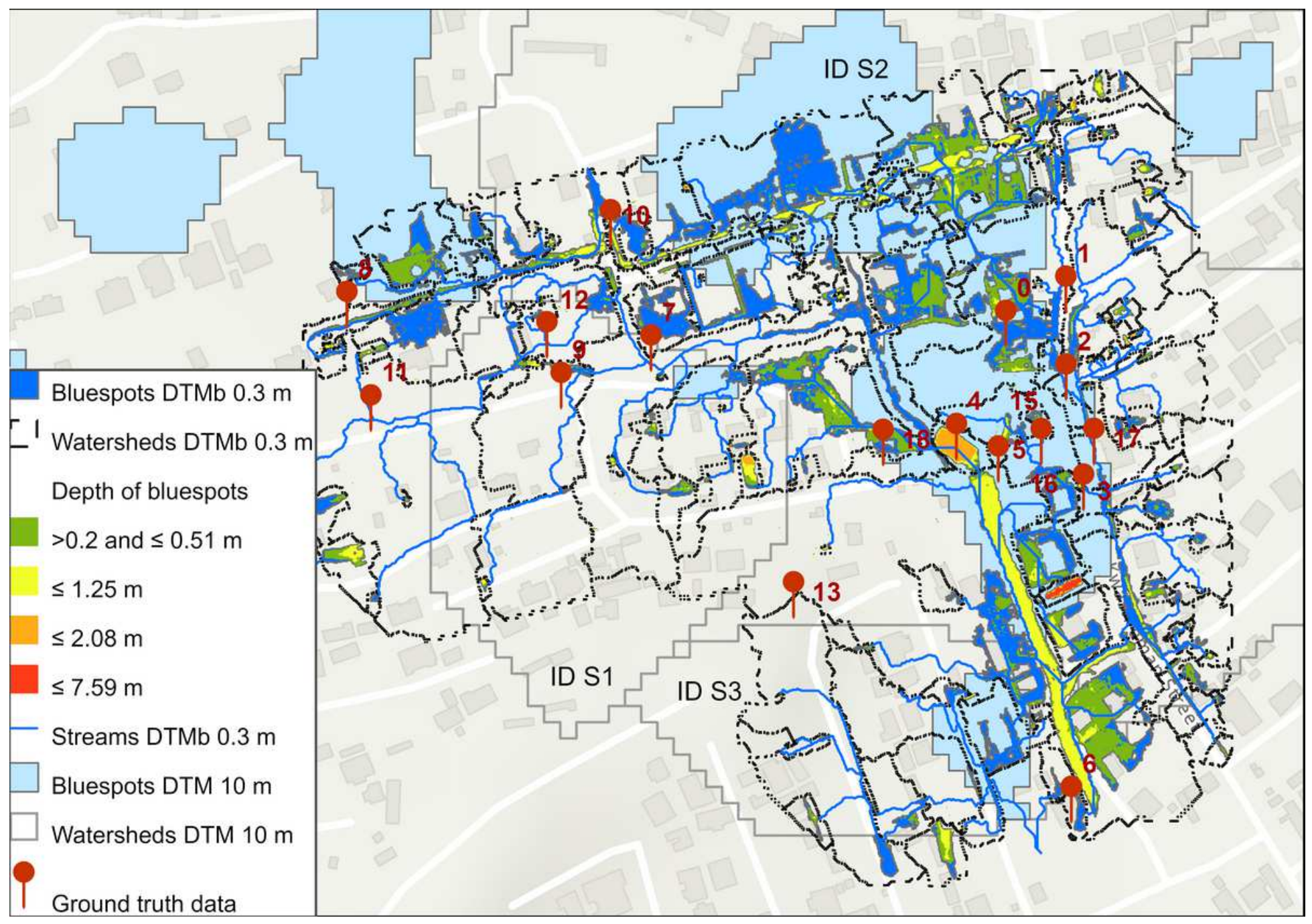

\section{Figure 4}

Comparison of bluespot extents in the Santa Maria site as simulated by applying the semi-low resolution DTM and the high resolution DTMb generated by the UAV-LiDAR. The bluespots' depths for flood modelling at the local scale were classified and colored accordingly. Streams are represented by blue lines and watersheds by dashed black lines. Watersheds modelled at the city-wide scale (ID S1, S2 and S3) are represented by black lines 


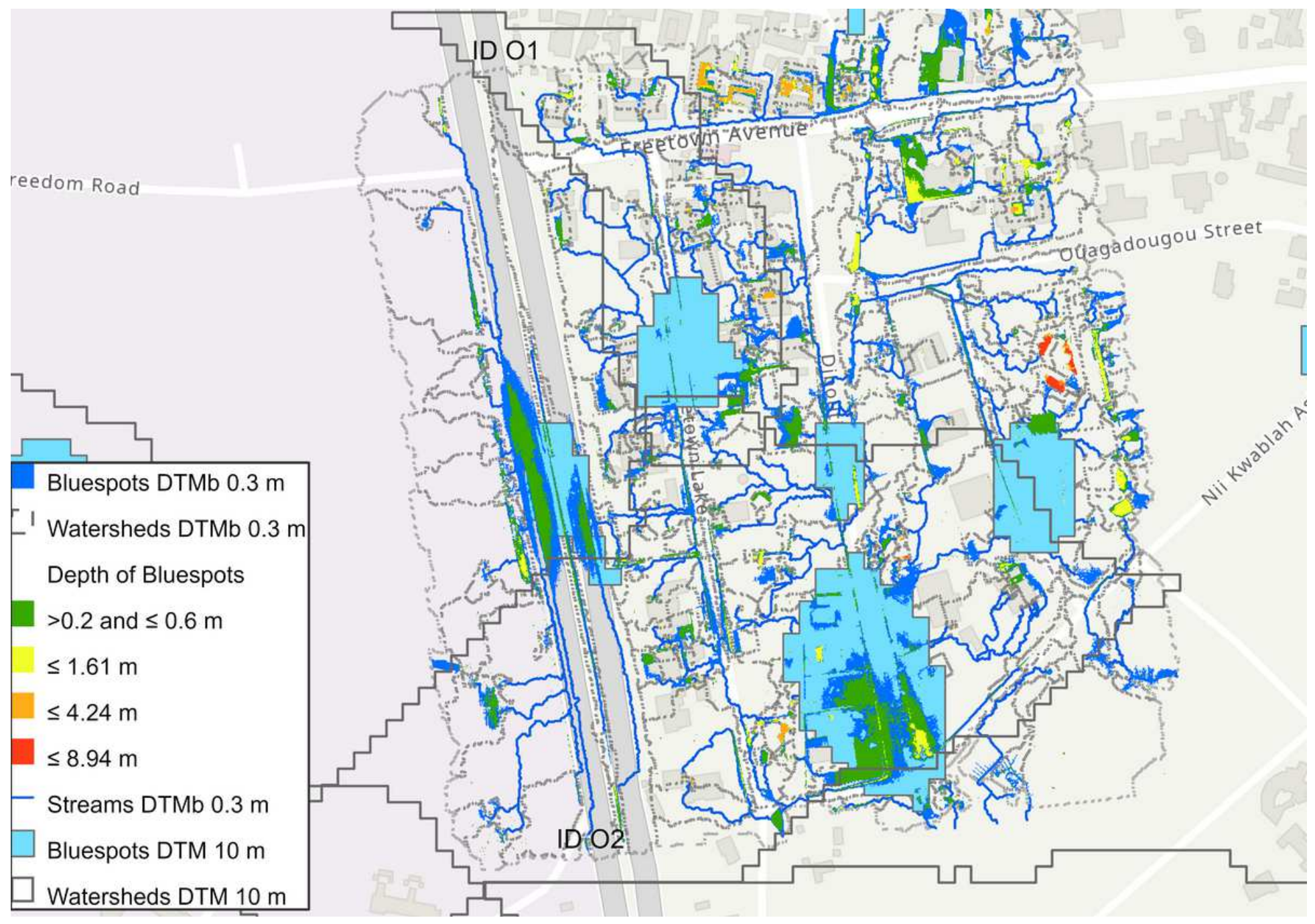

Figure 5

Comparison of bluespot extents in the Okponglo site as simulated by applying the semi-low resolution DTM and the high resolution DTMb generated by the UAV-LiDAR. The bluespots' depths for flood modelling at the local scale were classified and colored accordingly. Streams are represented by blue lines and watersheds by dashed black lines. Watersheds modelled at the city-wide scale $($ ID 01, 02) are represented by black lines 


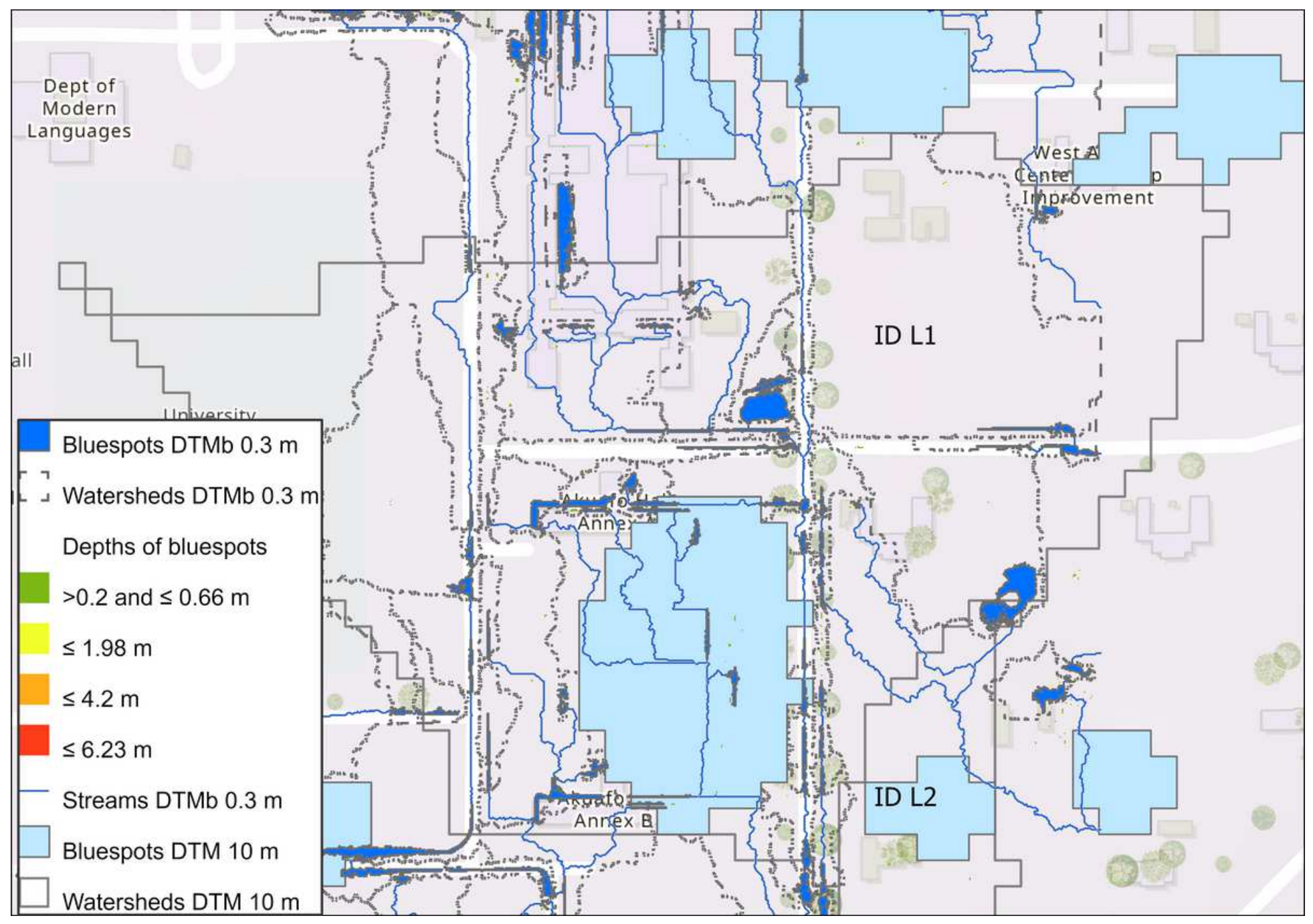

Figure 6

Comparison of bluespot extents in the Legon Hall site as simulated by applying the semi-low resolution DTM and the high resolution DTMb generated by the UAV-LiDAR. The bluespots' depths for flood modelling at the local scale were classified and colored accordingly. Streams are represented by blue lines and watersheds by dashed black lines. Watersheds modelled at the city-wide scale (ID L1, L2) are represented by black lines 

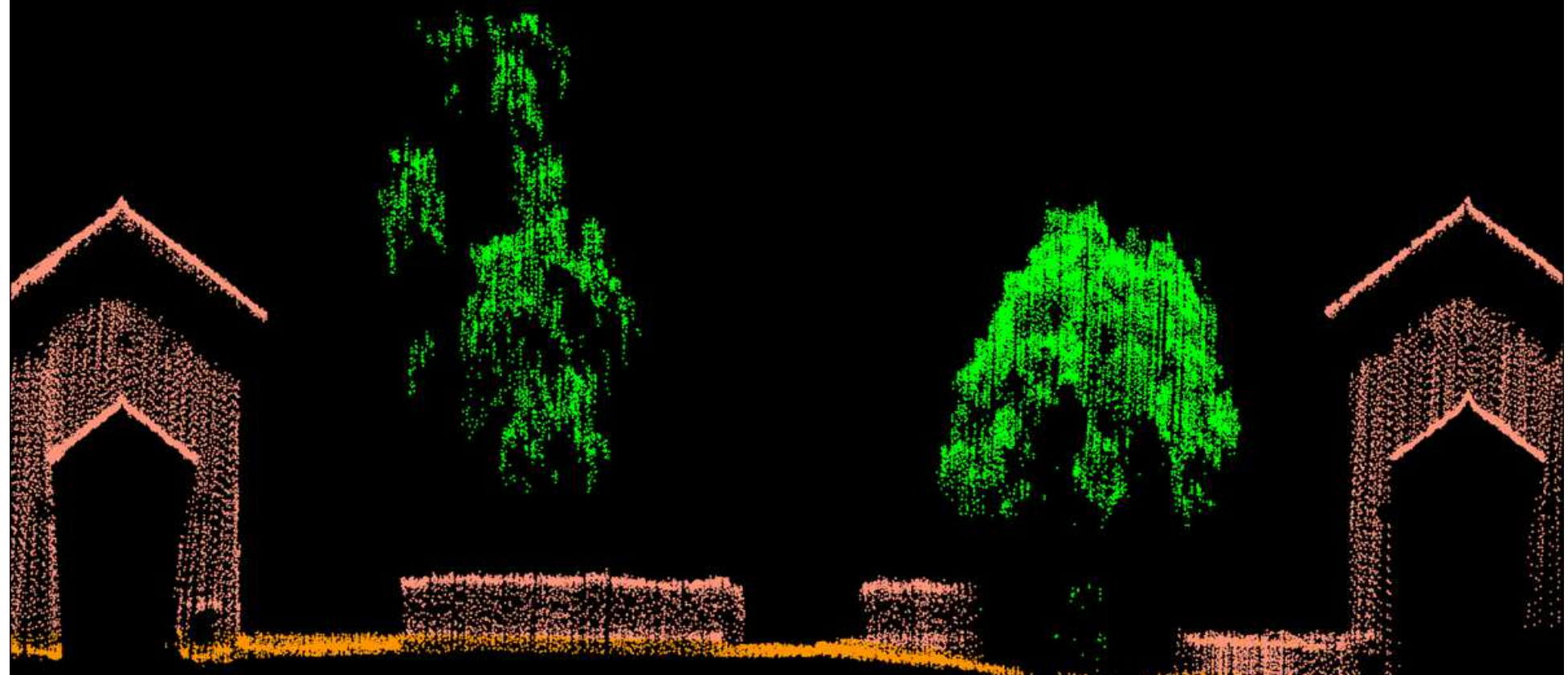

7.

(5)

Hox

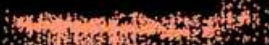

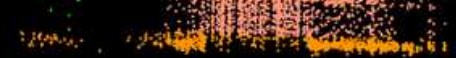

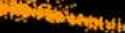

\section{Figure 7}

Extracted point clouds representing archways, trees and concrete fences

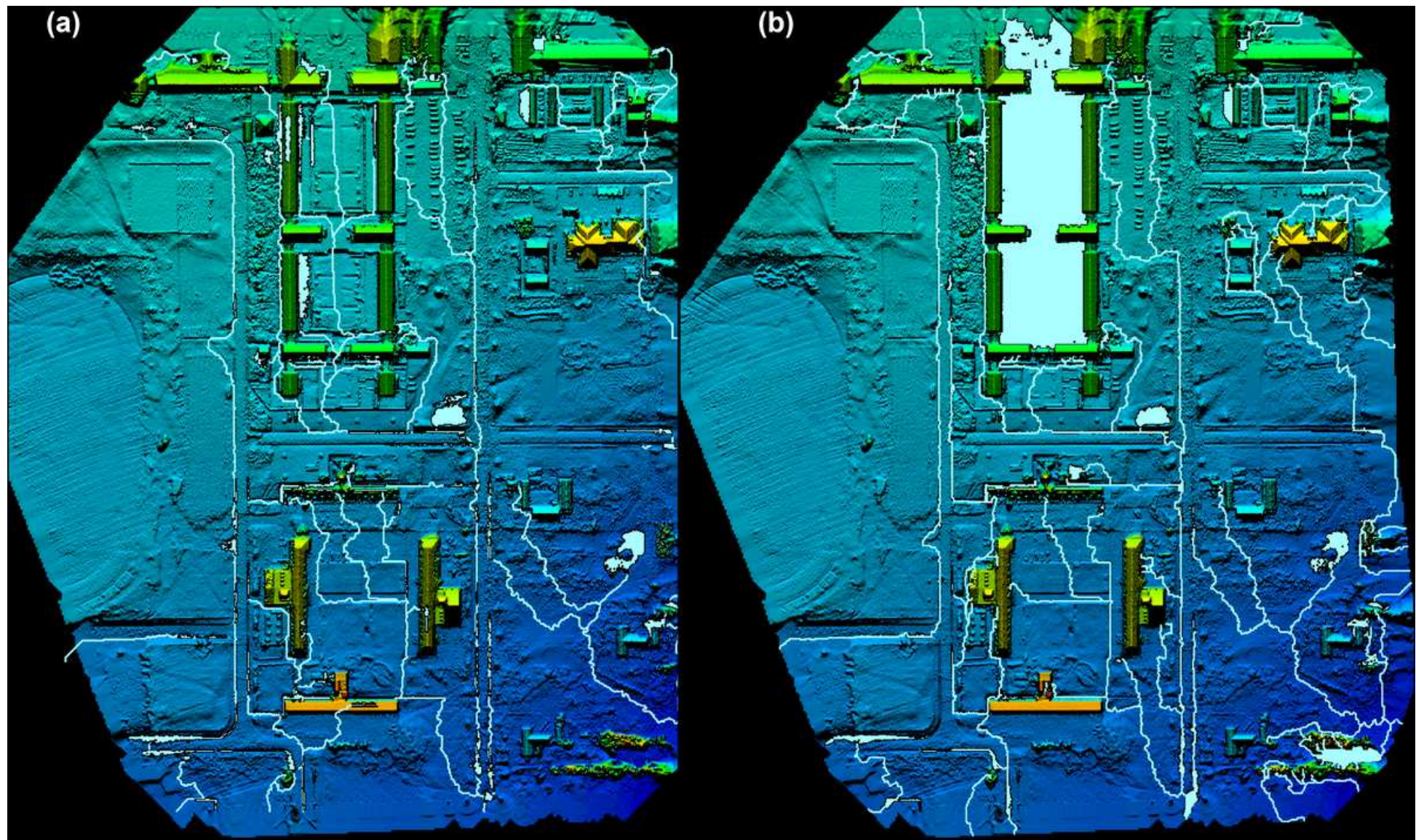




\section{Figure 8}

Digital Terrain Models featuring building information and excluding vegetation (DTMb) with simulated streams and bluespots after: a) misrepresentation of archways as buildings and b) after preserving archways to the DTMb

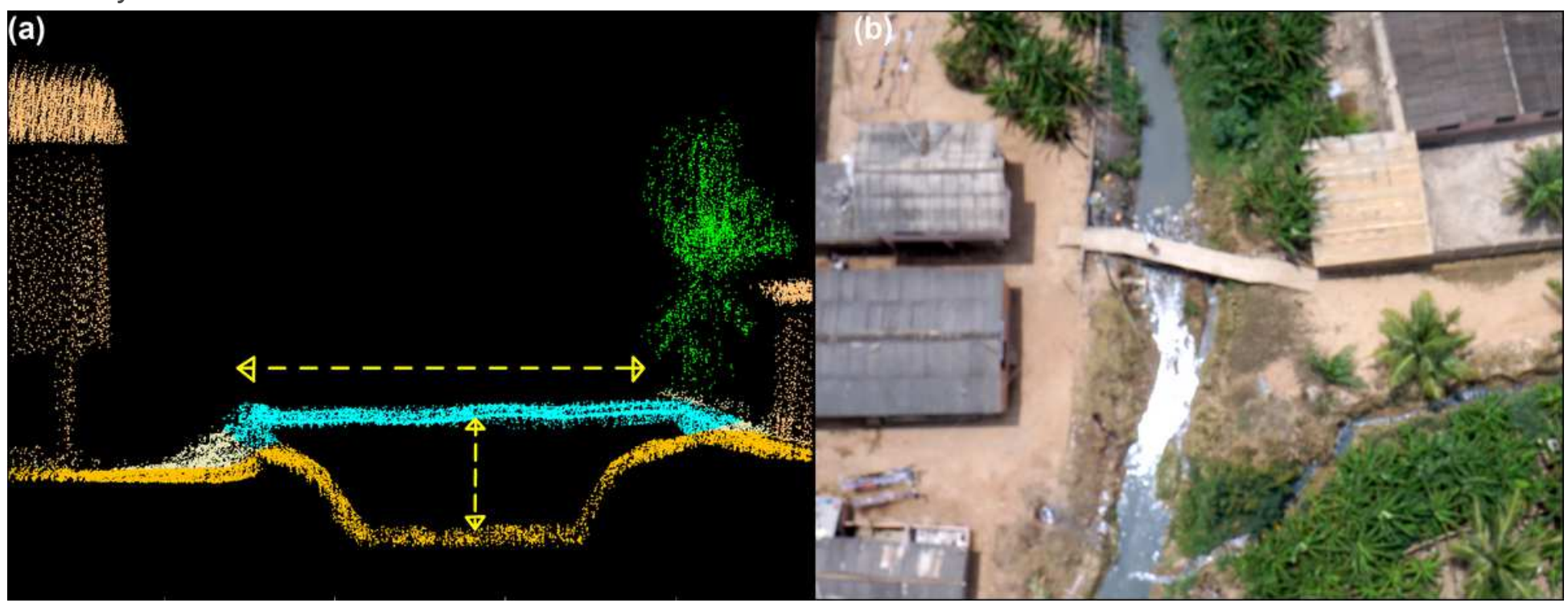

\section{Figure 9}

Profile view of downstream parts for a small bridge in point cloud format collected by the UAV LiDAR and aerial view of the bridge; both collected for validating the point cloud precision 


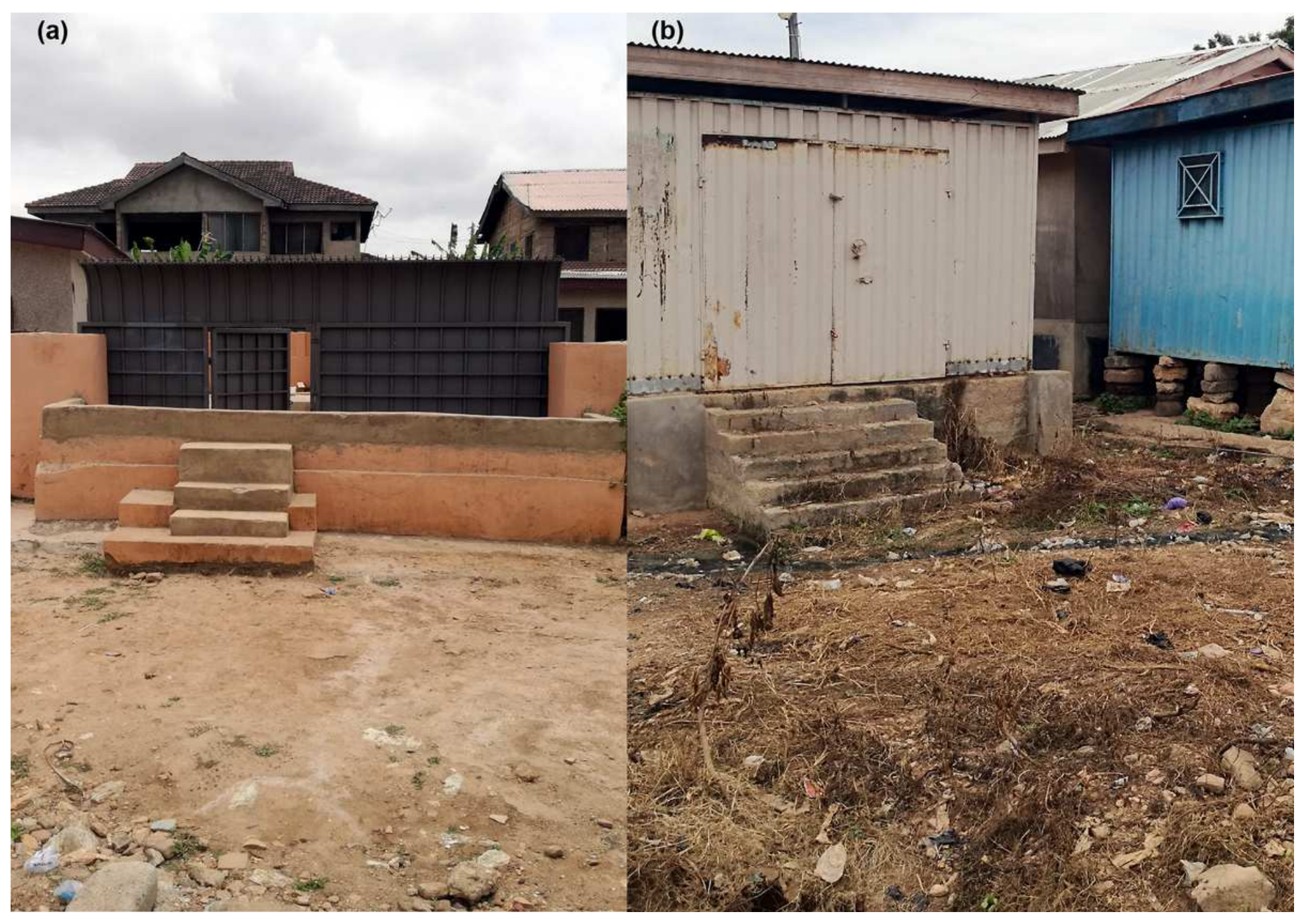

Figure 10

Ground photos corresponding to the ground truth points 12 and 16 in Fig. 4, where the height of the boundary walls was measured to indicate water levels during floods 


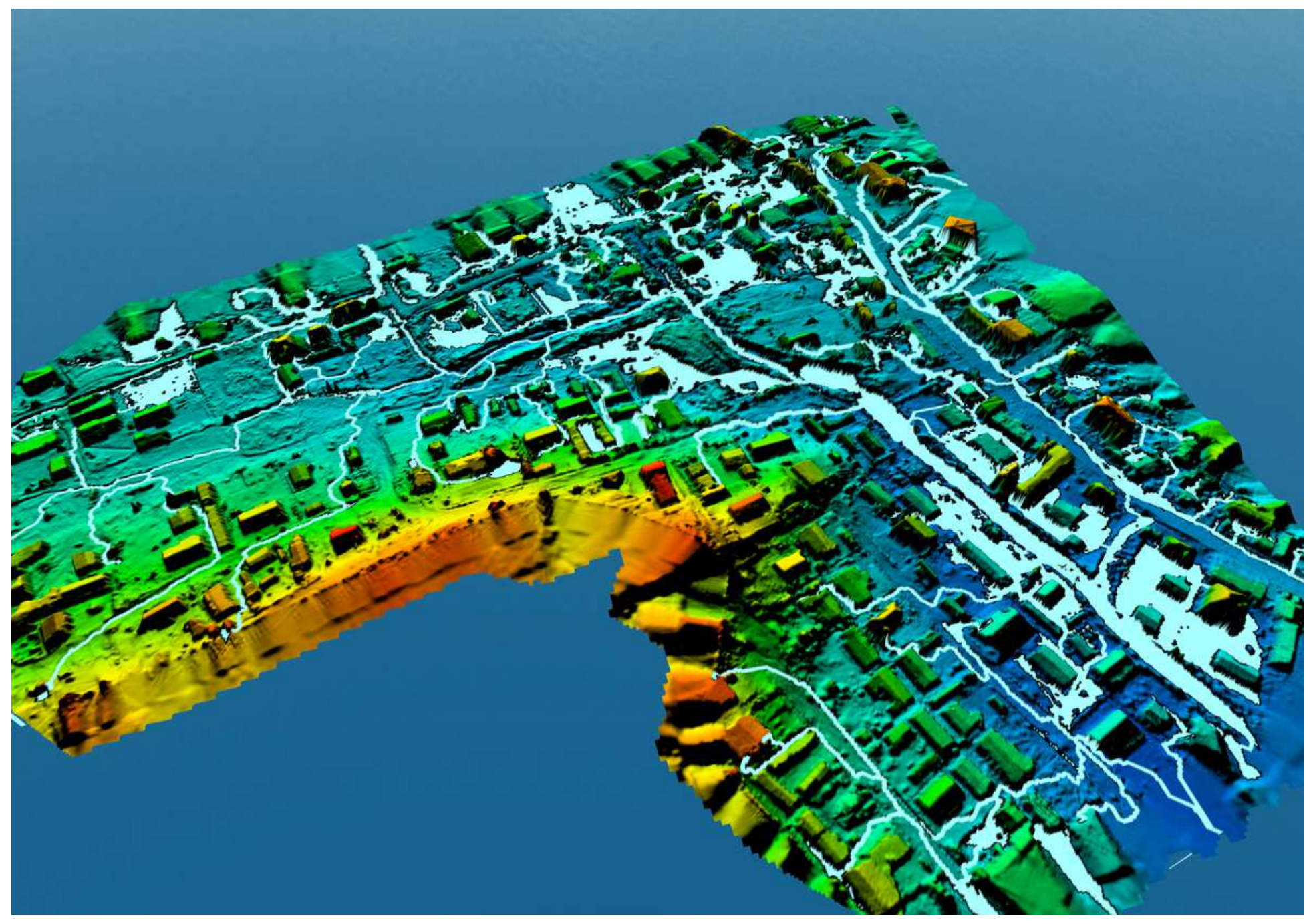

Figure 11

A 3D view of the DTMb for the Santa Maria area surveyed by the UAV-LiDAR, illustrating terrain, buildings and concrete walls. Local sinks (polygons) and streams (lines) were simulated at the local scale 


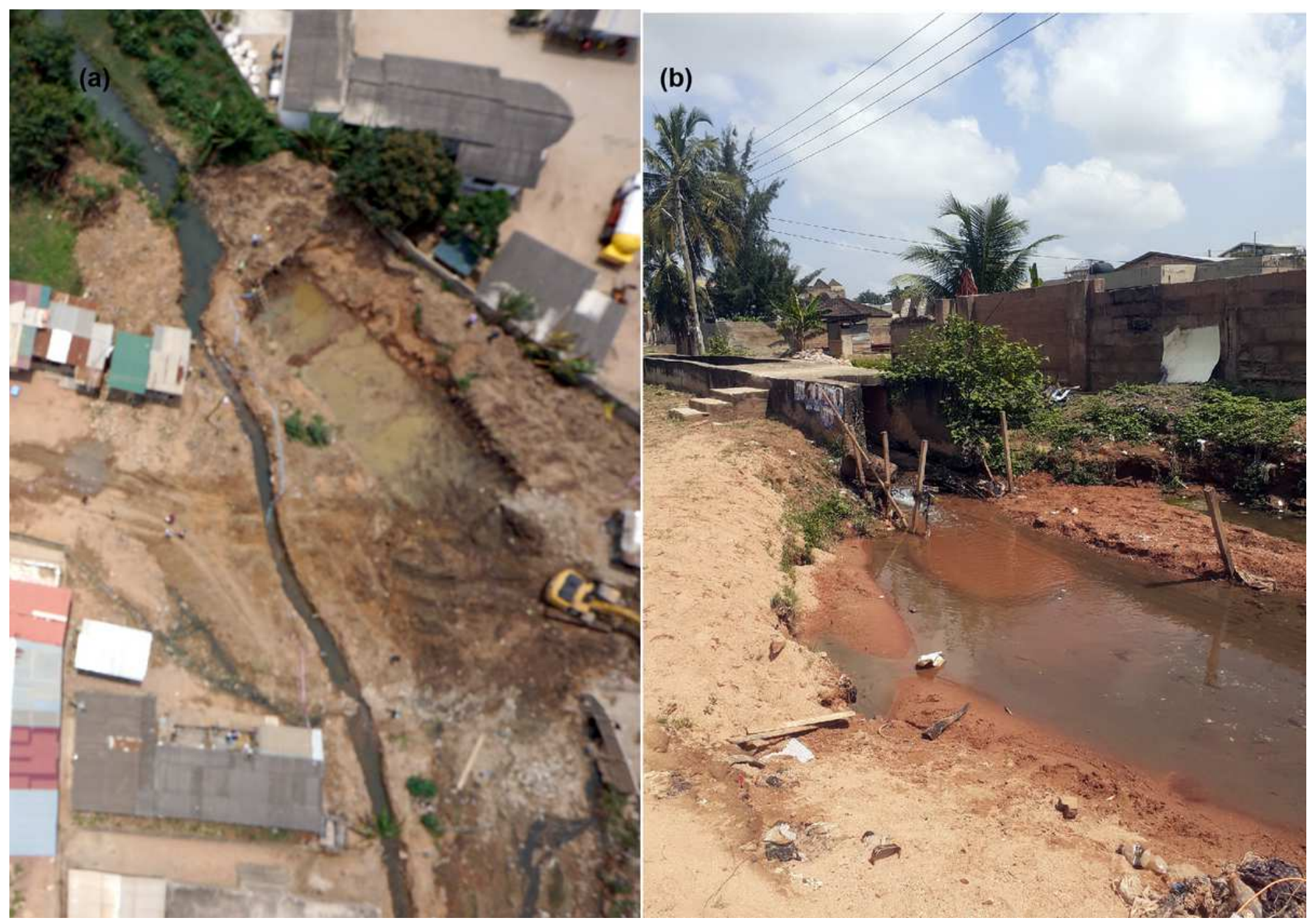

Figure 12

a) Aerial photograph capturing a location where a flood-prone bridge is enlarged causing a sink with a considerable depth, and b) evidence of erosion in a partial drain due to spill-over from uphill areas 